\title{
Inhibitory Effects and Anti-Invasive Activities of Trehalose Liposomes on the Proliferation of Lung Carcinoma Cells
}

Keiji Kuwabara, Hideaki Ichihara and Yoko Matsumoto*

Division of Applied Life Science, Graduate School of Engineering, Sojo University, 4-22-1 Ikeda, Nishi-ku, Kumamoto 860-0082, Japan

"Corresponding author: Yoko Matsumoto, Division of Applied Life Science, Graduate School of Engineering, Sojo University, 4-22-1 Ikeda, Nishi-ku, Kumamoto 860-0082, Japan, Tel: +81 96326 3965; Fax: +81 96323 1331; E-mail: matumoto@life.sojo-u.ac.jp

Received date: January 16, 2017; Accepted date: January 20, 2017; Published date: January 25, 2017

Copyright: (c) 2017 Kuwabara K, et al. This is an open-access article distributed under the terms of the Creative Commons Attribution License, which permits unrestricted use, distribution, and reproduction in any medium, provided the original author and source are credited.

\begin{abstract}
Inhibitory effects and anti-invasive activities of trehalose liposomes (DMTreC14) composed of L- $\alpha$ dimyristoylphosphatidylcholine and $\alpha$-D-glycopyranosyl-a-D-glucopiranoside monomyristate (TreC14) on the proliferation of human non-small cell lung carcinoma (A549) cells were examined in vitro. DMTreC14 with a hydrodynamic diameter less than $100 \mathrm{~nm}$, were preserved for 4 weeks. The inhibitory effects of DMTreC14 on the proliferation of A549 cells accompanied with apoptosis were obtained. Enhancement of the accumulation of DMTreC14 into A549 membranes was observed. An increase in cellular membrane fluidity of A549 cell treated with DMTreC14 was observed on the basis of fluorescence depolarization method. DMTreC14 caused apoptosis for A549 cells through the activation of caspases and mitochondrial pathway. The anti-migration effects of DMTreC14 for A549 cells were observed through the inhibition of filopodia formation. The anti-invasion effects with the reduction of MMP-14 of DMTreC14 for A549 cells were obtained.
\end{abstract}

Keywords: Trehalose liposomes; Lung carcinoma; Invasion; Apoptosis

\begin{abstract}
Abbreviations DMPC: L- $\alpha$-Dimyristoylphosphatidylcholine; DMTreC14: Treharose Liposomes composed of DMPC and TreC14; MMP-14: Matrix Metalloproteinase-14; NBDPC: 1-Palmitoyl-2-[12[(7-nitro-2-1,3-benzoxadiazol-4-yl)amino]dodecanoyl]-sn-glycero-3phosphocholine; TreC14: $\alpha$-D-glycopyranosyl- $\alpha$-D-glucopyranoside monomyristate.
\end{abstract}

\section{Introduction}

Lung cancer can be roughly classified into small cell and non-small cell lung cancer (NSCLC), which is the greater part of lung cancer. Molecular targeted therapeutics for NSCLC have been developed such as bevacizumab [1] and gefitinib [2]. However, there have been severe side effects in those therapies [3,4]. Therefore, novel treatment methods with no side effects are required to improve quality of life for patients.

Sugars play many roles in the life of the animals. To maintain life, the cells need a carbohydrate chain in adhesion, intercellular molecular recognition and transmission of the information between living cells. In the trehalose of disaccharides, specific binding on liposome of the trehalose with a high hydration power has been reported [5]. Protection effects for toxicity by cryopreservation of human erythrocytes have been shown [6]

Trehalose liposomes have been produced by using sonication of a mixture of phosphatidylcholine and trehalose surfactants in buffer solutions with no organic solvent [7]. Inhibitory effects of trehalose liposomes on the growth of tumor cells along with apoptosis have been reported [7-9]. Growth inhibition against colon, gastric, hepatocellular and leukemia cells has been obtained using trehalose liposomes without drugs. However, inhibitory effects and anti-invasive activities of trehalose liposomes on the growth of lung carcinoma have not yet been examined.

In this study, we investigated induction of apoptosis and invasive inhibition by DMTreC14 composed of L- $\alpha$ dimyristoylphosphatidylcholine (DMPC) and $\alpha$-D-glycopyranosyl- $\alpha$ D-glucopyranoside monomyristate (TreC14) for non-small cell lung carcinoma (A549) cells.

\section{Experimental Section}

\section{Preparation of DMTreC14}

DMTreC14 were prepared using sonicator (VS-N300; VELVO, Tokyo, Japan) after the mixing DMPC (purity $>99 \%$; NOF Co. Ltd., Tokyo, Japan) and TreC14 (Dojindo Ltd., Kumamoto, Japan) in 5\% glucose solution at $45^{\circ} \mathrm{C}$ with $300 \mathrm{~W}$, and then filtrated with a $0.45 \mu \mathrm{m}$ filter [7-9].

\section{Dynamic light scattering measurements}

The diameter $\left(\mathrm{d}_{\text {hy }}\right)$ of DMTreC14 was measured by a light scattering spectrometer (ELS-8000, Otsuka Electronics, Osaka, Japan) using He - Ne laser $(633 \mathrm{~nm})$ at scattering angle $=90^{\circ}[7-9]$.

\section{Cell culture}

Human non-small cell lung carcinoma (A549) cell lines were purchased from the Riken Cell Banc (Ibaraki, Japan). A549 cells were cultured in D-MEM medium (Life Technologies, Carlsbad, CA, USA) including $10 \%$ fetal bovine serum (FBS, HyClone Laboratories Inc., UT, USA), penicillin (100 unit $/ \mathrm{ml})$ and streptomycin $(50 \mu \mathrm{g} / \mathrm{ml})$ in incubator humidified at atmosphere of $5 \% \mathrm{CO}_{2}$ and at $37^{\circ} \mathrm{C}[10,11]$. 


\section{Analysis of apoptosis by DMTreC14 using flowcytometer}

Cells were seeded at a density of $1.0 \times 105$ cells per dish and incubated in a humidified atmosphere of $5 \% \mathrm{CO}_{2}$ at $37^{\circ} \mathrm{C}$ for $24 \mathrm{~h}$. DMTreC14 was added into each dish and the dishes were incubated. Cells were centrifuged and suspended in PBS (-) containing $1 \mathrm{mg} / \mathrm{ml}$ RNase, $0.1 \%$ Triton $\mathrm{X}-100$ and $40 \mu \mathrm{g} / \mathrm{ml}$ propidium iodide (PI, Molecular Probes, Eugene, OR, USA) in a dark room. The percentage of apoptotic cells was analyzed using a flow cytometer (Epics XL system II, Beckman Coulter, Brea, CA, USA) [9].

\section{Fusion and accumulation of DMTreC14 into the cell membrane}

The fusion and accumulation into the A549 cell membranes of DMTreC14 including a fluorescence probe (1-palmitoyl-2-[12-[(7nitro-2-1,3-benzoxadiazol-4-yl)amino]-dodecanoyl]-sn-glycero-3phosphocholine (NBDPC; Avanti Polar Lipids, Alabama, USA) was performed using confocal laser microscopy (TCS-SP; Leica Microsystems, Berlin, Germany) [7-9]. A549 cells $\left(2.0 \times 10^{5}\right.$ cells/ml $)$ were incubated in a humidified incubator at $37^{\circ} \mathrm{C}$ and $5 \% \mathrm{CO}_{2}$ for 24 h. The A549 cells were treated with DMTreC14/NBDPC ([DMPC] $=0.1$ $\mathrm{mM}$, [TreC14] $=0.259 \mathrm{mM},[\mathrm{NBDPC}]=0.1 \mu \mathrm{M})$ for $4 \mathrm{~h}$ and were observed using confocal laser microscopy with a $488 \mathrm{~nm}$ Ar laser line (detection at 505-555 nm).

\section{Measurement of cellular membrane fluidity}

The membrane fluidity of A549 cells was measured using spectrophotofluorometer (F-4500; HITACHI) on the basis of the fluorescence depolarization method [9]. A549 cells were labeled with DPH (1,6-diphenyl-1,3,5-hexatriene, Nacalai Tesque, Japan). The fluorescence depolarization (P) value of DPH in cells treated with DMTreC14 was measured.

\section{Measurements of caspase activity with Flowcytometer}

A549 cells $\left(1.0 \times 10^{5}\right)$ cells were treated with DMTreC14. After $24 \mathrm{~h}$ of incubation, each substrate solution (PhiPhiLux-GID2, CaspaLux 8LID2, CaspaLux 9-MID2 for caspase-3, caspase-8, and caspase-9, respectively; OncoImmunin Inc., Gaithersburg, MD, USA) was added to the A549 cells [7-9]. A549 cells were incubated for $45 \mathrm{~min}$ at $37^{\circ} \mathrm{C}$. After washing twice with $1 \mathrm{ml}$ of ice-cold PBS (-), the A549 cells were resuspended in $1 \mathrm{ml}$ fresh PBS (-). Caspase activity was determined and analyzed using a flow cytometer.

\section{Mitochondrial membrane potential}

3,3-Dihexyloxacarbocyanine iodide [DiOC6(3)] (Molecular Probes, Oregon, USA) were added in A549 cells treated with DMTreC14 $([\mathrm{DMPC}]=0.1 \mathrm{mM},[\mathrm{TreC} 14]=0.233 \mathrm{mM})$ to evaluate mitochondrial transmembrane potential $(\Delta \psi \mathrm{m})$ [7-9]. The stained A549 cells were investigated using flow cytometry with a $15 \mathrm{~mW} 488 \mathrm{~nm}$ air-cooling Ar laser and FL1 sensor (505-545 nm).

\section{Observation of filopodia formation by fluorescence microscopy}

The formation of filopodia in the A549 cells was analyzed using confocal laser microscopy. The cells $\left(2.0 \times 10^{4}\right.$ cells $\left./ \mathrm{mL}\right)$ were treated with $200 \mu \mathrm{M}$ DMTreC14 for 3 hours. After fixing with $10 \%$ formaldehyde, the A549 cells were incubated with of rhodamine phalloidin (Molecular Probes) for $30 \mathrm{~min}$. The stained A549 cells were observed with confocal laser microscopy [11].

\section{Scratch wound assay}

The migration of A549 cells was performed by scratch wound assay [12-15]. The A549 cells $\left(2.5 \times 10^{5}\right)$ cells/ml were cultured in medium with $10 \%$ FBS until they adhered. The monolayers of A549 cells were then carefully wounded using a $200 \mu \mathrm{l}$ sterile pipette tip. The wounded A549 cells were treated with or without $100 \mu \mathrm{M}$ DMTreC14. The wounded A549 cells were photographed using a light microscope (EVOS fl, Life Technologies, CA. USA) after $19 \mathrm{~h}$ incubation within the doubling time $(22 \mathrm{~h})$ of A549 cells in ATCC protocol. The migration areas were measured using an ImageJ (Version 1.46r, National Institutes of Health, Bethesda, MD, USA).

\section{Assessment of expression values of MMP-14 by flow cytometry}

A549 cells $\left(1.0 \times 10^{5}\right)$ cells were seeded in dishes and incubated for $24 \mathrm{~h}$. A549 cells were treated with DMTreC14 $(40 \mu \mathrm{M})$ for $24 \mathrm{~h}$. After cells were fixed with $10 \%$ formaldehyde for $30 \mathrm{~min}$ in the wells. A549 cells then were incubated with anti-MMP14 rabbit monoclonal antibody (Abcam plc, Cambridge, UK) $(5 \mu \mathrm{g} / \mathrm{ml})$ at room temperature for $30 \mathrm{~min}$ and stained Alexa Fluor $488^{\circ}$ Goat Anti-Mouse IgG (10 $\mu \mathrm{g} / \mathrm{ml}$ ) antibody in shaded box at $4^{\circ} \mathrm{C}$ for $1 \mathrm{~h}$. Stained A549 cells were measured by a flow cytometer $[12,16,17]$.

\section{Statistical analysis}

Data are given as mean \pm SD Statistical comparisons were made using Student's t-test. $\mathrm{P}<0.05$ was considered to represent a statistically significant difference.

\section{Results}

\section{Physical properties of DMTreC14}

We examined the morphology of DMTreC14 on the basis of dynamic light scattering measurements. DMTreC14 with a hydrodynamic diameter less than $100 \mathrm{~nm}$ was kept for 4 weeks. In contrast, DMPC liposomes were unstable and precipitated at 14 days after the preparation.

\section{Induction of apoptosis of DMTre for A549 cells}

We evaluated the apoptotic DNA rate of A549 cells treated with DMTreC14 using flow cytometry. Results are shown in Figure 1A. Apoptotic DNA rate increased after the treatment with DMTreC14 as the dose of DMTreC14 increased. The apoptotic DNA rate reached a high apoptotic rate (95\%). The data indicated that DMTreC14 induced apoptosis for A549 cells. Suppression effects of DMTreC14 on the proliferation of A549 cells were investigated using WST-8 assay by the methods described previously [7-9]. DMTreC14 dose-dependently suppressed the proliferation of A549 cells, and showed $40 \mu \mathrm{M}$ of $50 \%$ inhibitory concentration (IC50) for A549 cells. In contrast, DMPC liposomes showed no inhibition (IC50=450 $\mu \mathrm{M}$ ). To investigate the pathways of apoptosis caused by DMTreC14 for A549 cells, we examined activation of caspases in A549 cells treated with DMTreC14 on the basis flow cytometric analysis as shown in Figure 1B. Enhanced activities of caspase- $3,-8$ and -9 were obtained, suggesting that DMTreC14 induced apoptosis of A549 cells by the activation of those 
Citation: Kuwabara K, Ichihara H, Matsumoto Y (2017) Inhibitory Effects and Anti-Invasive Activities of Trehalose Liposomes on the Proliferation of Lung Carcinoma Cells. J Carcinog Mutagen 8: 283. doi:10.4172/2157-2518.1000283

Page 3 of 5

caspases. Next, we examined the mitochondrial pathway in apoptosis induced by DMTreC14 for A549 cells. The results are shown in Figure 1C. The decreased mitochondrial transmembrane potential of A549 cells after the treatment with DMTreC14 was obtained.

A

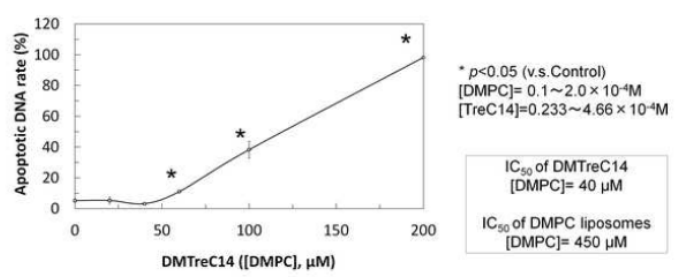

B
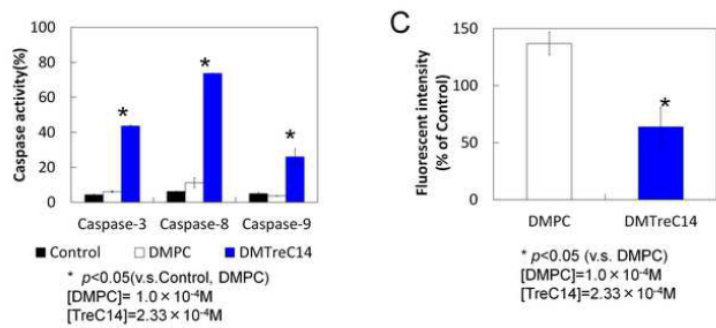

Figure 1: The induction of apoptosis for A549 cells induced by DMTreC14. (A) Induction of apoptosis toward A549 cells treated with DMTreC14. (B) Caspase activation for A549 cells treated with DMTreC14. (C) Decrease in mitochondrial transmembrane potential of A549 cells treated with DMTreC14.

\section{Fusion and accumulation of DMTreC14 into A549 cells}

The fusion and accumulation of DMTreC14 for A549 cells was examined on the basis of a confocal laser microscope. The results are shown in Figure 2A. Increased accumulation of DMTreC14 including NBDPC as a fluorescence probe was observed, although no accumulation of DMPC was obtained.

We examined membrane fluidity of A549 cells on the basis of the fluorescence polarization $(\mathrm{P})$ analysis. The results are shown in Figure 2B. The P value decreased in A549 cells treated with DMTre, indicating the increase of membrane fluidity of A549 cells.
A

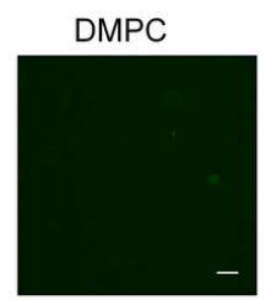
DMTreC14

B

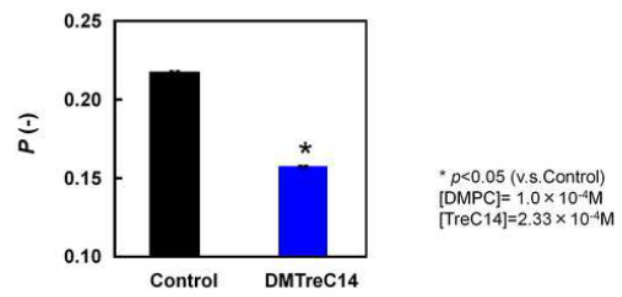

Figure 2: (A) Accumulation of DMTreC14 (DMTre/NBDPC) including fluorescence probe in the plasma membranes of A549 cells. (B) Membrane fluidity in membrane of A549 cells treated with DMTreC14.

\section{Suppression on migration of A549cells by DNTreC14}

We investigated the anti-invasion effects of DMTreC14 associated with suppression of cell motility. The anti- migration effects of DMTreC14 on the migration capability of cells was analyzed on the basis of a scratch wound assay [12-15]. The results are shown in Figure 3A. Inhibitory effects of DMTreC14 on the migration of A549 compared with control cells were obtained. The anti-migration effects of DMTreC14 were investigated at low concentrations $(40 \mu \mathrm{M})$ without affecting growth-inhibition under IC50 values $(40 \mu \mathrm{M})$. The treatment with DMTreC14 markedly inhibited migration of A549 cells as compared with control cells.

By the way, filopodia formation on the surface of tumor cells plays an important role in the invasion and migration into the surrounding tissue [18-20]. Accordingly, the suppression effects of DMTreC14 on the filopodia formation of A549 cells were observed by confocal laser microscopy. Results are shown in Figure 3B. Few filopodia on the surface of A549 cells treated with DMTreC14 $(40 \mu \mathrm{M})$ for $3 \mathrm{~h}$ was observed, although many filopodia in the control and DMPC were obtained. 
Page 4 of 5

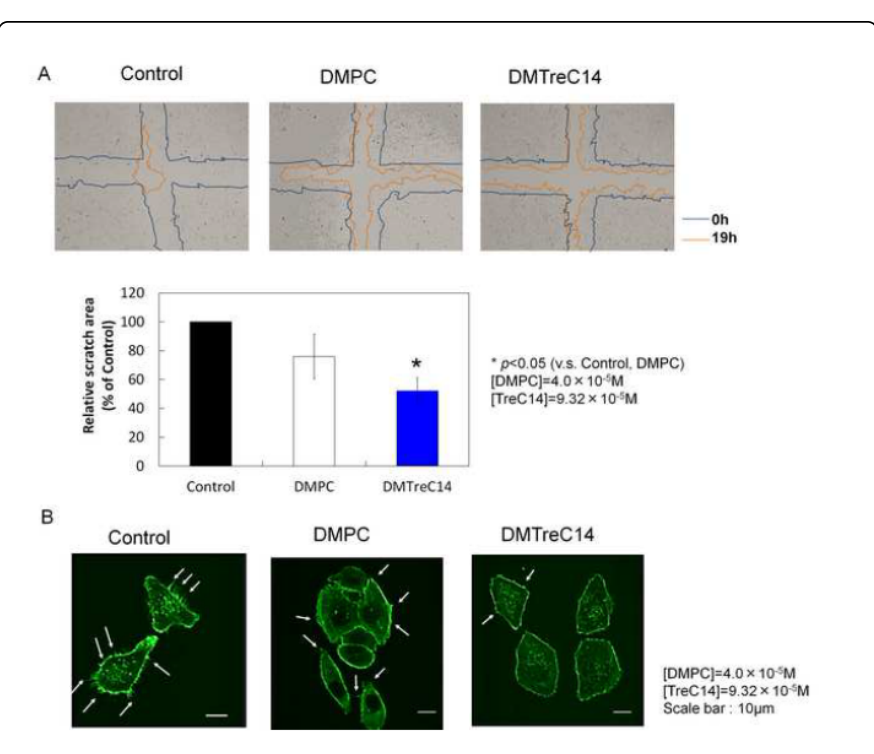

Figure 3: Suppression on the migration of A549 cells by DMTreC14 on the basis of scratch wound method. (A) Blue lines indicate initial wound area; red lines indicate migrating cells. Relative migration area of 549 cells in the absence or presence of DMTreC14 for $19 \mathrm{~h}$. (B) Suppression on the filopodia formation of A549 cells by DMTreC14. The cells stained with rhodamine phalloidine observed using confocal laser microscopy. Scale bars: $10 \mu \mathrm{m}$. Allows indicate the filopodia formation in A549 cells.

\section{Inhibitory effects of DMTreC14 on invasion}

MMP-14 is a transmembrane metalloprotease. MMP-14 involves invasion process such as activation of pro-MMP2 and pericellular proteolysis. To clarify effects of DMTreC14 on invasion, we examined expression rate of membrane type 1 metalloprotease (MMP-14) in A549 cells treated with DMTreC14 on the basis of immunostaining by a flow cytometer. The results are shown in Figure 4. The relative expression rate of MMP-14 in A549 cells after the treatment with DMTreC14 decreased as compared with the control and DMPC. The inhibition of MMP-14 in A549 cells after the treatment with DMTreC14 was observed. These results suggest that DMTreC14 should inhibit the invasion of A549 cells in vitro.

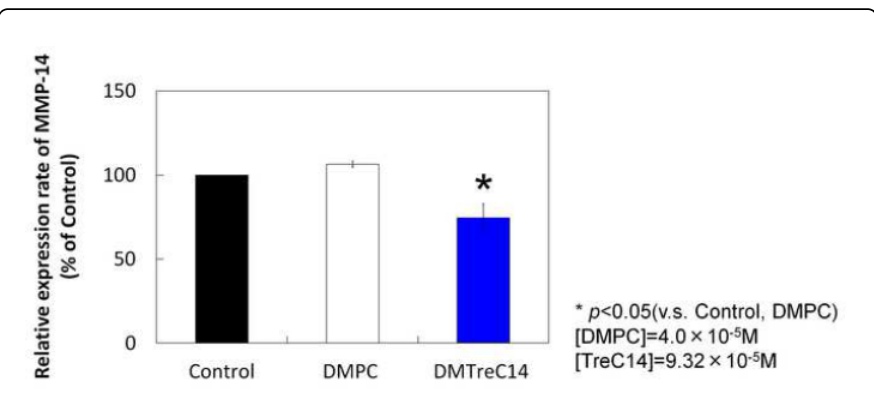

Figure 4: Relative expression rate of MMP-14 in A549 cells after the treatment with DMTreC14 $(40 \mu \mathrm{M})$ for $24 \mathrm{~h}$. Data represent the mean $(\mathrm{n}=3) \pm \mathrm{SE}^{*} \mathrm{p}<0.05$ ( vs. control and DMPC).

\section{Discussion}

Chemotherapy with molecular targeted drug such as bevacizumab [1] and gefitinib [2] is effective for patients with NSCLC. However, many clinical studies have indicated several limitations to the application in those therapies [3,4]. Although they kill tumor cells, chemotherapy damage normal cells. Therefore, novel therapeutic agents without side-effects are desirable.

The inhibitory effects of trehalose liposomes (DMTreCn) composed of DMPC and DMTreC14 on the growth of human colon carcinoma, gastric carcinoma and lymphoma in vitro were reported [7-9]. Remarkably high inhibitory effects (IC50 $=40 \mu \mathrm{M}$ ) of DMTreC14 on the proliferation of A549 cells obtained. In contrast, DMPC liposomes showed no inhibition $(\mathrm{IC} 50=450 \mu \mathrm{M})$. The thickness of the fixed aqueous layer of DMTreCn was larger than that of DMPC liposomes and increased in a dose-dependent manner $[7,8]$. Therefore, inhibitory effects of DMTreC14 could be related to hydration in tumor cells.

Increased accumulation of DMTreC14 including NBDPC as a fluorescence probe was observed, although no accumulation of DMPC was obtained. In addition, remarkably high accumulation into stomach, liver and colon carcinoma cell membranes of DMTreCn has been confirmed $[7,8]$. In contrast, accumulation in DMPC was undetected $[7,8]$. These results suggest that DMTreC14 could have higher suppression effects on the proliferation of A549 cells as compared with DMPC. Increased membrane fluidity of A549 cells treated with DMTreC14 was obtained on the basis of the fluorescence polarization $(\mathrm{P})$ analysis. Enhanced fluidity of cell membrane in the apoptosis for tumor cells has been reported $[18,19]$. These results suggest that DMTreC14 fused into A549 cells and then increased fluidity of the cell membrane.

The induction of apoptosis and their pathways of apoptosis by DMTreCn have been reported for human colon carcinoma and gastric carcinoma cells $[7,8]$. Enhanced activities of caspase-3, -8 and -9 in A549 cells treated with DMTreC14 were obtained. The decreased mitochondrial transmembrane potential of A549 cells after the treatment with DMTreC14 was obtained. The data indicate that DMTreC14 caused apoptosis through the mitochondria pathway for A549 cells. That is, the apoptotic signal first passes through the mitochondria, caspase- 9 and caspase- 3 , then through caspase- 8 and caspase- 3 after the fusion and accumulation into A549 cell membrane, and then reaches the nucleus. DMTreC14 activated caspases 3, 8, and 9 and the apoptotic signal passed through mitochondria. These results indicate that DMTreC14 induced apoptosis toward A549 cells through the activation of caspases- $3,-8$ and -9 and mitochondria.

Tumor cell invasion is an important early step in the process of tumor metastasis. Remarkably inhibitory effects of DMTreC14 on migration of A549 cells were obtained as compared with that on control cells. Interestingly, the anti-invasive effects of DMTreC14 were observed at low concentrations $(40 \mu \mathrm{M})$ without affecting growthinhibition. Actin cytoskeleton dynamics, such as lamellipodia and filopodia formation on the surface of tumor cells plays an important role in the invasion and migration into the surrounding tissue [18-22]. The treatment with DMTreC14 drastically inhibited the filopodia formation in A549 cells. These results suggest that the DMTreC14 inhibited migration of A549 cells and could be related to suppressing the filopodia formation.

MMP-14 is a transmembrane metalloprotease. MMP-14 involves invasion process such as activation of pro-MMP2 and pericellular proteolysis. The inhibition of MMP-14 in A549 cells after the treatment 
with DMTreC14 was observed. These results suggest that DMTreC14 should inhibit the invasion of A549 cells in vitro. Inhibitory effects and anti-invasive activities of trehalose liposomes (DMTreC14) on the proliferation were obtained for the first time and apoptotic signal transduction by DMTreC14 was clarified.

\section{Conclusion}

We clarified for the first time that inhibitory effects and antiinvasion activities of trehalose liposomes (DMTreC14) were obtained on the proliferation of human non-small cell lung carcinoma (A549) cells accompanied with apoptosis through the specific accumulation of DMTreC14 into the A549 cell membranes. The noteworthy aspects are as follows: (a) DMTreC14 with a hydrodynamic diameter less than 100 $\mathrm{nm}$ were kept for 4 weeks. (b) The inhibitory effects of DMTreC14 on the proliferation of A549 cells were obtained accompanied with apoptosis. (c) DMTreC14 fused into A549 cells and then increased fluidity of cell membrane. (d) The anti-migration effects of DMTreC14 for A549 cells were obtained through the suppression of filopodia formation. (e) The inhibition of MMP-14 in A549 cells treated with DMTreC14 was observed. It is noteworthy that remarkably high inhibitory effects and anti-invasion activities of DMTreC14 on the proliferation of A549 cells accompanied with apoptosis were indicated in vitro.

\section{Acknowledgments}

We thank Masataka Kuwano for his technical assistance.

\section{References}

1. Johnson DH, Fehrenbacher L, Novotny WF, Herbst RS, Nemunaitis JJ, et al. (2004) Randomized phase II trial comparing bevacizumab plus carboplatin and paclitaxel with carboplatin and paclitaxel alone in previously untreated locally advanced or metastatic non-small-cell lung cancer. J Clin Oncol 22: 2184-2191.

2. Ranson M, Hammond LA, Ferry D, Kris M, Tullo A, et al. (2002) ZD1839, a selective oral epidermal growth factor receptor-tyrosine kinase inhibitor, is well tolerated and active in patients with solid, malignant tumors: results of a phase I trial. J Clin Oncol 20: 2240-2250.

3. Tassinari D, Sartori S, Papi M, Drudi F, Castellani C, et al. (2011) Bevacizumab in the treatment of advanced, non-squamous non-small cell lung cancer: an evidence-based approach. Oncology 80: 350-358.

4. Reck M, Gatzemeier U (2005) Benefit in lung function improvement and side-effect profile of long-term responders: an analysis of 14 NSCLC patients treated for at least 9 months with gefitinib. Lung Cancer 50: 107-114.

5. Luzardo MC, Amalfa F, Nuñez AM, Díaz S, Biondi De Lopez AC, et al. (2000) Effect of trehalose and sucrose on the hydration and dipole potential of lipid bilayers. Biophys J 78: 2452-2458.

6. Stoll C, Holovati LJ, Acker PJ, Wolkers FW (2012) Synergistic Effects of Liposomes, Trehalose, and Hydroxyethyl Starch for Cryopreservation of Human Erythrocytes. Biotechnol Prog 28: 364-371.
7. Matsumoto Y, Cao E, Ueoka R (2013) Novel liposomes composed of dimyristoylphosphatidylcholine and trehalose surfactants inhibit the growth of tumor cells along with apoptosis. Biol Pharm Bull 36: 1258-1262.

8. Matsumoto Y, Cao E, Ueoka R (2013) Growth inhibition by novel liposomes including trehalose surfactant against hepatocarcinoma cells along with apoptosis. Anticancer Res 33: 4727-4740.

9. Matsumoto Y, Kuwabara K, Ichihara H, Kuwano M (2016) Therapeutic effects of trehalose liposomes against lymphoblastic leukemia leading to apoptosis in vitro and in vivo. Bioorg Med Chem Lett 26: 301-305.

10. Regmi SC, Park SY, Kim SJ, Banskota S, Shah S, et al. (2015) The AntiTumor Activity of Succinyl Macrolactin A Is Mediated through the $\beta$ Catenin Destruction Complex via the Suppression of Tankyrase and PI3K/Akt. PLoS One 10: e0141753.

11. Komizu Y, Yukihara M, Matsumoto Y, Ueoka R (2014) Cell cycle arrest by hybrid liposomes for human lung carcinoma cells. J Carcinog Mutagen 5: 1000157.

12. Ichihara H, Komizu Y, Ueoka R, Matsumoto $Y$ (2015) Inhibitory effects of hybrid liposomes on the growth of non-small cell lung carcinoma cells and anti-invasive activity by ceramide generation without any drugs. J Carcinog Mutagen 6: 1000230.

13. Vermeulen K, Van Bockstaele DR, Berneman ZN (2003) The cell cycle: a review of regulation, deregulation and therapeutic targets in cancer. Cell Prolif 36: 131-149.

14. Massagué J (2004) G1 cell-cycle control and cancer. Nature 432: 298-306.

15. Liang CC, Park AY, Guan JL (2007) In vitro scratch assay: a convenient and inexpensive method for analysis of cell migration in vitro. Nat Protoc 2: 329-333.

16. Jujo T, Sakao S, Tsukahara M, Kantake M, Maruoka M, et al. (2014) The role of matrix metalloproteinase in the intimal sarcoma-like cells derived from endarterectomized tissues from a chronic thromboembolic pulmonary hypertension patient. PLoS One 9: e87489.

17. Xu M, Wang YZ (2013) miRâ€'133a suppresses cell proliferation, migration and invasion in human lung cancer by targeting MMP14. Oncol Rep 30: 1398-1404.

18. Fujimoto K, Iwasaki C, Kawaguchi H, Yasugi E, Oshima M (1999) Cell membrane dynamics and the induction of apoptosis by lipid compounds. FEBS Lett 446: 113-116.

19. Lacour S, Hammann A, Grazide S, Lagadic-Gossmann D, Athias A, et al. (2004) Cisplatin-induced CD95 redistribution into membrane lipid rafts of HT29 human colon cancer cells. Cancer Res 64: 3593-3598.

20. Xiao X, Xiao Y, Wen R, Zhang Y, Li X, et al. (2015) Promoting roles of the secreted frizzled-related protein 2 as a Wnt agonist in lung cancer cells. Oncol Rep 34: 2259-2266.

21. Hou SY, Li YP, Wang JH, Yang SL, Wang Y, et al. (2016) Aquaporin-3 Inhibition Reduces the Growth of NSCLC Cells Induced by Hypoxia. Cell Physiol Biochem 38: 129-140.

22. Zhao H, Jiao Y, Zhang Z (2015) Deguelin inhibits the migration and invasion of lung cancer A549 and H460 cells via regulating actin cytoskeleton rearrangement. Int J Clin Exp Pathol 8: 15582-15590. 